\title{
Full Factorial Design Analysis of Carbon Nanotube Polymer-Cement Composites
}

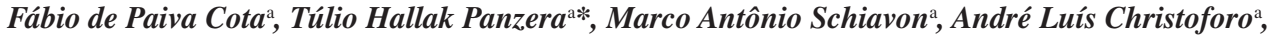 \\ Paulo Henrique Ribeiro Borges ${ }^{\mathrm{b}}$, Chris Bowen ${ }^{\mathrm{c}}$,Fabrizio Scarpa ${ }^{\mathrm{d}}$ \\ a Department of Mechanical Engineering, Federal University of São João del Rei - UFSJ, \\ São João Del Rei, MG, Brazil \\ ${ }^{\mathrm{b}}$ Department of Civil Engineering, Federal Centre of Technology Education of Minas Gerais - CEFET/MG, \\ Belo Horizonte, $M G$, Brazil \\ ${ }^{\mathrm{c}}$ Materials Science, University of Bath, Bath, United Kingdom \\ ${ }^{\mathrm{d} B r i s t o l}$ Centre for Nanoscience and Quantum Information, \\ University of Bristol, Bristol, United Kingdom
}

Received: February 22, 2012; Revised: April 19, 2012

\begin{abstract}
The work described in this paper is related to the effect of adding carbon nanotubes (CNT) on the mechanical properties of polymer-cement composites. A full factorial design has been performed on 160 samples to identify the contribution provided by the following factors: polymeric phase addition, CNT weight addition and water/cement ratio. The response parameters of the full factorial design were the bulk density, apparent porosity, compressive strength and elastic modulus of the polymer-cement-based nanocomposites. All the factors considered in this analysis affected significantly the bulk density and apparent porosity of the composites. The compressive strength and elastic modulus were affected primarily by the cross-interactions between polymeric phase and CNT additions, and the water/cement ratio with polymeric phase factors.
\end{abstract}

Keywords: carbon nanotubes, mechanical properties, cement-based composites, Design of Experiments (DOE)

\section{Introduction}

A significant portion of nanoscience and nanotechnology research initiatives focuses on the creation of new molecules and submicron systems with very different architectures and special multiphysics properties ${ }^{1}$. One of the most public examples of these nano-materials systems is constituted by carbon nanotubes (CNTs). CNTs are sheets of carbon atoms in a hexagonal arrangement, rolled to form a cylindrical tube, where the walls are constituted by single or multiple carbon atoms (MWCNTs) ${ }^{1}$. It is possible to find in open literature examples about the incorporation of carbon nanotubes into structural materials such as cement and polymers ${ }^{1-3}$. The addition of CNTs into composite matrices leads to significant changes of some aspects of their material properties. Besides using carbon nanotubes, cement-based composites have been traditionally produced adding a polymeric phase. The use of polymeric inclusions in cement is a practice developed mainly in Japan and Europe in the 1970's and the United States in the 1980's, in order to enhance the physical and mechanical properties of the cement matrix ${ }^{4,5}$. In terms of microstructure, the polymeric phase tends to coat unhydrated grains of cement which delays partially, or completely, the hydration process. In some cases, the presence of polymers in the cement provides more internal $\mathrm{C}_{3} \mathrm{~S}$ products than external ones, and prevents the formation of ettringite crystals during the initial

*e-mail: panzera@ufsj.edu.br hydration ${ }^{6-7}$. However, adding polymer inclusions in cement leads to a sensible reduction of porosity, with consequent decrease of free paths for crack propagation and enhanced mechanical strength ${ }^{8}$.

Panzera et al. ${ }^{9}$ investigated the effect of epoxy resin on the mechanical behaviour of white Portland cement. The cement/polymer composites were mixed with varying resin weight percentages $(25 \%, 50 \%$ and $75 \%)$ without the presence of water. The results revealed that the presence of the polymeric phase leads to an increase of strength and a reduction of the bulk density, compared to pure cement. Based on FTIR analysis it was observed that the formation of hydrated cement grains can occur due to the presence of epoxy resin ${ }^{10}$. Panzera et al. ${ }^{11}$ also investigated the effect of adding thermoset polymer $(25,50$ and $75 \mathrm{wt}$. (\%)) and water content $(0 \%$ and $30 \%)$ into cementitious composites. The addition of polymer inclusions provided not only a reduction of the apparent density and porosity, but also an increase of the compressive strength of the composites. It was also verified that the presence of water contributed to decrease the mechanical strength of cement-based composites.

Carbon nanotubes do not only provide an enhancement of strength and toughness in nanocomposites, but they can also be used as piezoresistive sensors in smart materials. Experimental results conducted by $\mathrm{Yu}$ and Kwon ${ }^{12}$ showed that the electrical resistance of cementitious composites manufactured with CNT changed when a stress field was 
applied, thus indicating a significant potential as stress/strain sensors for civil engineering structures. The use of a chemical additive provided a homogeneous dispersion of CNT into the cement paste, which can however affect the characteristics of the piezoresistive composite. A higher level of CNTs dispersed in the composite may increase the sensitivity of the material as a piezoelectric sensor ${ }^{12}$.

When adding epoxy resin into the cement paste, one can obtain in principle a material with interesting mechanical characteristics from a structural engineering perspective (low density, high toughness and strength). However, for complex heterogeneous materials such as cement-based composites with polymer inclusions, the effect of adding a nanophase to the constituents could be difficult to ascertain in a clear way, with other environmental factors possibly playing a role (water fraction, polymer/cement ratio, manufacturing process). This work describes from a rigorous factorial design of experiments procedure the effects of doping ceramic-polymer composite materials with carbon nanotubes addition into ceramic polymeric composite material. The investigated properties were the bulk density, the apparent porosity, compressive strength and Young's modulus. The parameters (or "factors") considered in the full-factorial analysis where the weight fraction of multi-walled carbon nanotubes, the water to cement ratio, and the polymeric phase weight addition. A total of 160 samples have been subjected to mechanical tensile and compressive tests as well as standard apparent porosity trials. The interaction effects between the different parameters and mechanical and physical properties of the nanocomposites have been evaluated using an analysis of variance on the mean values of the experimental results. To the best of the Authors' knowledge, this is the first large-scale attempt at establishing from experimental point of view relationships between the constituents of nano-cement-polymer composites and their physical and mechanical characteristics.

\section{Material and Methods}

\subsection{Portland cement}

The Portland cement used for all the samples was Brazilian CP V ARI PLUS (ASTM Type III) supplied by Holcim S.A. of Brazil. Table 1 describes the chemical and physical analysis of the Portland cement, which is in

Table 1. Chemical and physical analysis of Potland cement.

\begin{tabular}{cc}
\hline Chemical composition & Percentage $(\%)$ \\
\hline $\mathrm{SiO}_{2}$ & 19.45 \\
$\mathrm{CaO}$ & 64.14 \\
$\mathrm{Al}_{2} \mathrm{O}_{3}$ & 4.75 \\
$\mathrm{Fe}_{2} \mathrm{O}_{3}$ & 3.12 \\
$\mathrm{SO}_{3}$ & 2.85 \\
$\mathrm{CO}_{2}$ & 1.13 \\
$\mathrm{MgO}$ & 0.80 \\
$\mathrm{~K}_{2} \mathrm{O}$ & 0.66 \\
Physical properties & \\
Specific surface (Blaine) & 4729 \\
$\left(\mathrm{~cm}^{2} . \mathrm{g}^{-1}\right)$ & \\
\hline
\end{tabular}

accordance with the requirements of Brazilian standard $\left(\right.$ ABNT-NBR 11578) ${ }^{13}$.

\subsection{Thermoset polymer: epoxy resin}

The epoxy resin and the hardening agent used as polymeric phase were RQ-0100RF and RQ-0164RF PLUS respectively, and supplied by Alpha Resiqualy Company (Brazil). The stechiometric weight ratio between the resin and the hardener was set to $68.97 \%$ and $31.03 \%$, respectively.

\subsection{Carbon nanotubes (CNT)}

The multi-walled carbon nanotubes with outer diameter ranging from 10 to $40 \mathrm{~nm}$, length between 5 and $20 \mathrm{mM}$ and $95 \%$ of purity were supplied by CNT Co. Ltd., Incheon, Korea. The CNT addition was calculated on the total mass, and set as 0.7 wt. (\%).

Figure 1 shows a backscattered electron image of the CNTs using a scanning electron microscope (Model JSM $6330 \mathrm{~F})$. The samples were prepared without coating, using only a silver glue to fix the material on the metallic sample holder.

\subsection{Full factorial design}

The full factorial design of the type $\mathrm{n}^{\mathrm{k}}$ used consisted in investigating all possible combinations of the experimental factors (k) and their respective levels (n). The result of the factorial $\mathrm{n}^{\mathrm{k}}$ corresponds to the number of the investigated experimental conditions ${ }^{14,15}$. Table 2 shows the full factorial design type $3^{1} 2^{2}$, which represents a factor with three levels and two factors with two levels, providing 12 different experimental combinations. The responses investigated in this study were the bulk density, apparent porosity, compressive strength and modulus of elasticity.

The composites were bi-phase configurations made of Portland cement and the thermoset polymer. The cement addition was a complement of the polymer fraction - i.e., composites having 75 wt. (\%), 50 wt. (\%) and 25 wt. (\%) of epoxy resin possessed $25 \mathrm{wt}$. (\%), $50 \mathrm{wt}$. (\%) and $75 \mathrm{wt}$. (\%) of cement, respectively. The amount of water was calculated based on the cement addition. Besides the experimental

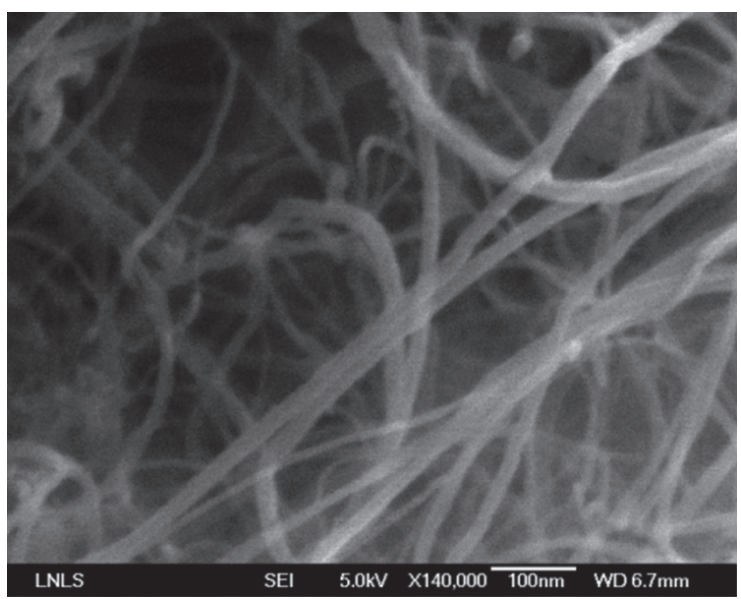

Figure 1. Carbon nanotubes image obtained by SEM in backscattered electron mode. 
conditions presented in Table 2, four reference conditions were prepared for comparison, which are presented in Table 3 .

\subsection{Specimen manufacturing and testing}

The raw materials (Portland cement, epoxy resin, water and $\mathrm{CNT}$ ) were mixed for 5 minutes using a small Hobart mixer. Plastic moulds were used to manufacture the cylindrical samples with the diameter of $20 \mathrm{~mm}$. The samples were vibrated for 1 minute and then sealed in plastic bags to avoid the presence of bubbles and desiccation. Samples were kept for 28 days at room temperature and at approximately $60 \%$ relative humidity. After curing, the samples were cut using a precision saw to ensure a constant sample height of $40 \mathrm{~mm}$ and the parallelism for compression testing. Tests for compressive strength and apparent porosity were conducted in accordance with the procedures described in BS EN ISO $604^{16}$ and BS EN ISO $10545-3^{17}$, respectively. The modulus of elasticity was determined with strain gauges of $10 \mathrm{~mm}$ in length supplied by Tokyo Sokki Kenkyujo Company.

Two replicates and a randomisation principle were carried out to provide a basis for analysing the experimental results ${ }^{15}$. The process of 'replication' ensured the validity of the estimate of the experimental error and provided a basis for inference in analyzing the experiments ${ }^{16}$. In addition to replication, the experiments were also randomised in terms of the order the treatments to provide protection against variables that are unknown to the experiment, but may impact the response ${ }^{8,9}$. Five specimens were manufactured

Table 2. Experimental conditions for the full factorial design type $3^{1} 2^{2}$.

\begin{tabular}{cccc}
\hline $\begin{array}{c}\text { Experimental } \\
\text { conditions }\end{array}$ & $\begin{array}{c}\text { Addition } \\
\text { of CNT }\end{array}$ & $\begin{array}{c}\text { Addition of } \\
\text { polymer } \\
\text { (wt. (\%)) }\end{array}$ & $\begin{array}{c}\text { Water/cement } \\
\text { ratio }\end{array}$ \\
\hline C1 & Yes & 75 & 0 \\
C2 & Yes & 75 & 0.30 \\
C3 & Yes & 50 & 0 \\
C4 & Yes & 50 & 0.30 \\
C5 & Yes & 25 & 0 \\
C6 & Yes & 25 & 0.30 \\
C7 & No & 75 & 0 \\
C8 & No & 75 & 0.30 \\
C9 & No & 50 & 0 \\
C10 & No & 50 & 0.30 \\
C11 & No & 25 & 0 \\
C12 & No & 25 & 0.30 \\
\hline
\end{tabular}

Table 3. Reference conditions.

\begin{tabular}{cccc}
\hline $\begin{array}{c}\text { Reference } \\
\text { conditions }\end{array}$ & $\begin{array}{c}\text { Addition } \\
\text { of CNT }\end{array}$ & $\begin{array}{c}\text { Addition of } \\
\text { polymer } \\
\text { (wt. (\%)) }\end{array}$ & $\begin{array}{c}\text { Water/cement } \\
\text { ratio }\end{array}$ \\
\hline CR1 & Yes & 100 & 0 \\
CR2 & Yes & 0 & 0.30 \\
CR3 & No & 100 & 0 \\
CR4 & No & 0 & 0.30 \\
\hline
\end{tabular}

for each experimental condition (see Figure 2), including the references, providing 160 samples in total.

\section{Results and Discussions}

Table 5 shows the results from the analysis of variance (ANOVA) related to the mean values of the response variables. The P-values indicate which of the effects in the system are statistically significant, based on the examination of the experimental data from replicate 1 and replicate 2 . If the $\mathrm{P}$-value is less than or equal 0.05 , the effect is considered significant. An $\alpha$-level of 0.05 is the level of significance, which implies a $95 \%$ of probability of the effect being significant ${ }^{15}$. The results are presented via 'main effect' and 'interaction' plots. These graphic plots cannot be considered typical 'scatter' plots, but rather illustrate the statistical analysis and provide the variation of the significant effects $^{16}$. The main effect of a factor must be individually interpreted only when there is no evidence of interaction with other factors. When one or more interaction effects of superior order are significant, the factors that interact might be mutually considered ${ }^{14}$.

The underlined values in Table 4 correspond to the significant conditions that are evaluated and presented in the graphs related to the main effect and/or interaction between factors. In order to facilitate the reading and understanding of the results, the following nomenclature will be adopted: $\mathrm{N}$ stands for $\mathrm{CNT}$ addition, $\mathrm{P}$ for polymeric phase addition and $\mathrm{C}$ for the water/cement ratio.

The value of ' $\mathrm{R}^{2}$ (adj)' shown in the ANOVA indicates how well the model predicts responses for new observations. Larger values of $R^{2}\left(R^{2}>0.90\right)$ suggest models of greater predictive ability ${ }^{14,15}$. Table 4 shows the values of $R^{2}$ (adj) for the responses, which were found being superior to $95 \%$, demonstrating that the quality of adjustment of the models has been satisfactory. The results for the reference conditions can be observed in Table 5 .

\subsection{Bulk density}

The bulk density data (Figure 3) for the composites varied from $1.25 \mathrm{~g} . \mathrm{cm}^{-3}$ to $1.87 \mathrm{~g} . \mathrm{cm}^{-3}$. The interaction effect between "addition of $\mathrm{CNT}^{*}$ addition of polymer* and addition of water" was significant, exhibiting a P-value of 0.011 .

It was observed that the presence of polymer inclusions leads to a reduction of the bulk density (Figure 3a). This result can be explained by the higher density of the cement phase $\left(\sim 1.93 \mathrm{~g} . \mathrm{cm}^{-3}\right)$ in comparison to the polymeric one

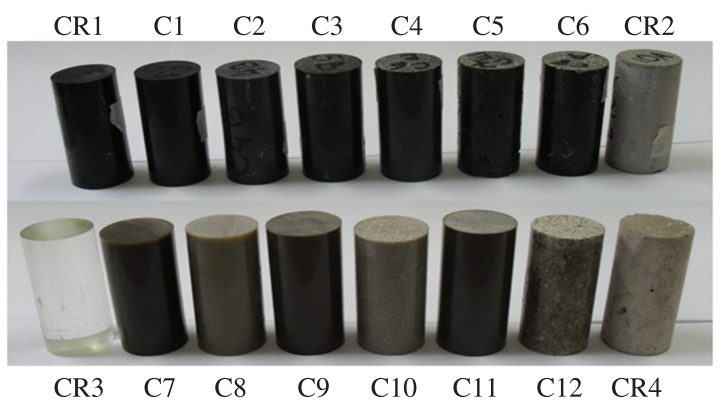

Figure 2. Cylindrical samples for the compression test setup. 
Table 4. Analyses of variance (ANOVA).

\begin{tabular}{|c|c|c|c|c|c|}
\hline \multicolumn{6}{|c|}{ P-value $<0,05$} \\
\hline & & Bulk density & Apparent porosity & Compressive strength & Modulus of elasticity \\
\hline \multirow{3}{*}{ 孠 } & $\mathrm{N}$ & 0.030 & 0.000 & 0.000 & 0.000 \\
\hline & $\mathrm{P}$ & 0.000 & 0.000 & 0.000 & 0.000 \\
\hline & W & 0.000 & 0.000 & 0.000 & 0.000 \\
\hline \multirow{6}{*}{ 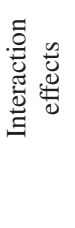 } & $\mathrm{N}^{*} \mathrm{P}$ & 0.076 & 0.000 & 0.005 & 0.000 \\
\hline & $\mathrm{N}^{*} \mathrm{~W}$ & 0.773 & 0.000 & 0.300 & 0.202 \\
\hline & $\mathrm{P}^{*} \mathrm{~W}$ & 0.000 & 0.000 & 0.007 & 0.006 \\
\hline & $\mathrm{N}^{*} \mathrm{P} * \mathrm{~W}$ & 0.011 & 0.000 & 0.524 & 0.242 \\
\hline & Variance & 0.0207 & 0.1277 & 3.1924 & 0.0696 \\
\hline & $\mathrm{R}^{2}$ (adj) & $99.10 \%$ & $99.82 \%$ & $95.92 \%$ & $99.40 \%$ \\
\hline
\end{tabular}

Table 5. Results for the reference conditions.

\begin{tabular}{llccc}
\hline \multicolumn{1}{c}{ Response variables } & CR1 & CR2 & CR3 & CR4 \\
\hline Bulk density $\left({\left.\mathrm{g} . \mathrm{cm}^{-3}\right)}_{\text {Apparent porosity }(\%)}\right.$ & $1.15 \pm 0.01$ & $1.70 \pm 0.01$ & $1.15 \pm 0.01$ & $1.93 \pm 0.02$ \\
Compressive strength $(\mathrm{MPa})$ & $0.43 \pm 0.06$ & $21.60 \pm 0.21$ & $0.23 \pm 0.07$ & $4.75 \pm 0.73$ \\
Modulus of elasticity $(\mathrm{GPa})$ & $60.0 \pm 2.1$ & $54.5 \pm 2.7$ & $66.7 \pm 3.1$ & $60.9 \pm 2.5$ \\
\hline
\end{tabular}

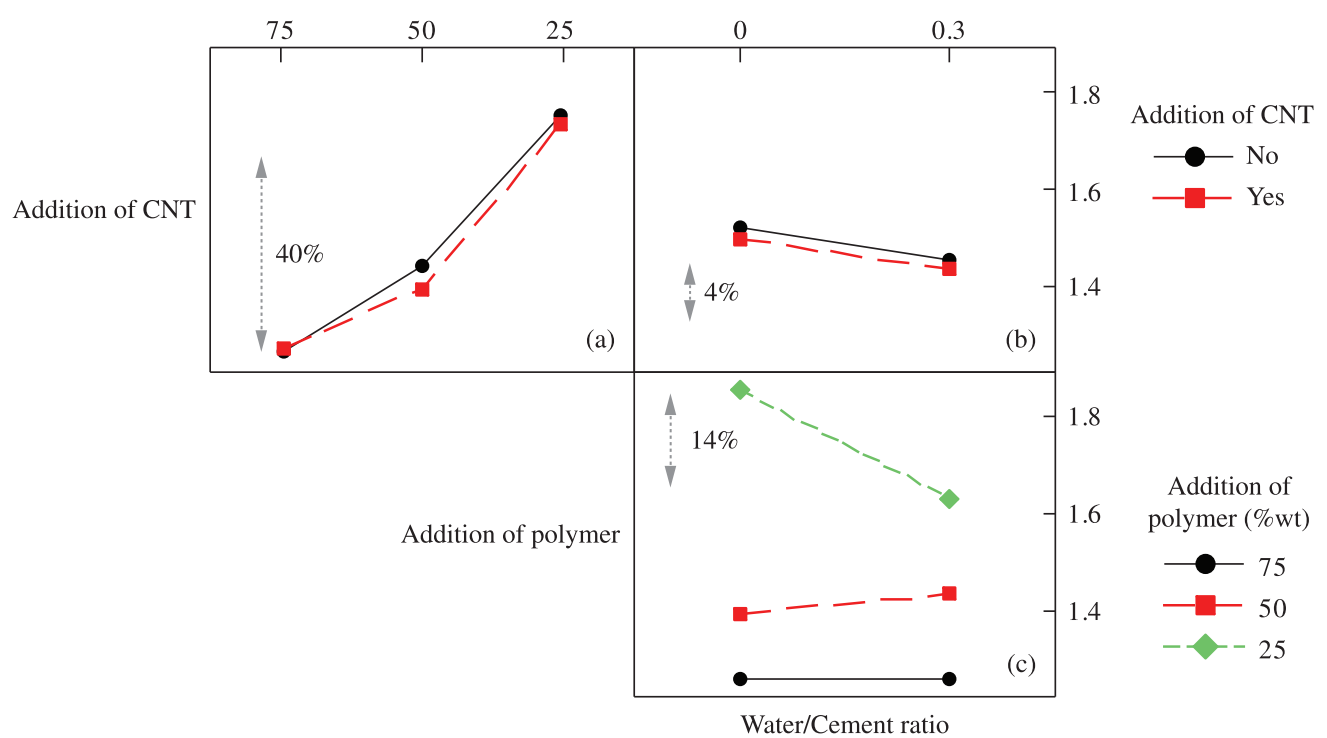

Figure 3. Interaction effect plot for the bulk density describing the addition of CNTs, the polymeric phase and water/cement ratio.

$\left(\sim 1.15{\mathrm{~g} . \mathrm{cm}^{-3}}\right.$, see Table 5). The inclusions of carbon nanotubes lead only to minor changes of the bulk density of the composites (see Figure 3a, b). The presence of water appeared to affect not only the hydration of cement-based products, but also the formation of pores, increasing as a consequence the volume of voids and reducing the overall density of the composite material. This effect can be observed in Figure 3b, with a reduction of $4 \%$ on the bulk density of the composite specimen. Figure $3 \mathrm{c}$ shows also a bulk reduction of $14 \%$ for composites made with $25 \mathrm{wt}$. (\%) of polymer, and $75 \mathrm{wt}$. (\%) of cement. The bulk density is significantly affected when the fraction of cement phase is increased, demonstrating the influence of water in the cement pores formation.

\subsection{Apparent porosity}

The third order interaction between "addition of CNT, addition of polymer and water/cement ratio" was significant, showing P-value of 0.000 (see Table 4). Figure 4 shows the graph of interaction effect for the apparent porosity response.

It was observed that the composites fabricated with the smallest addition of polymer (25\%) exhibited higher apparent porosity. This result is in accordance with the reference conditions results (see Table 5) and the bulk density results (see Figure 3).

Figure $4 \mathrm{a}$ shows the effect of constitutive phases and CNT addition on the porosity of the composites, with a 24-fold variation observed between the levels corresponding to $25 \mathrm{wt}$. (\%) and $75 \mathrm{wt}$. (\%) of polymeric phase additions. 


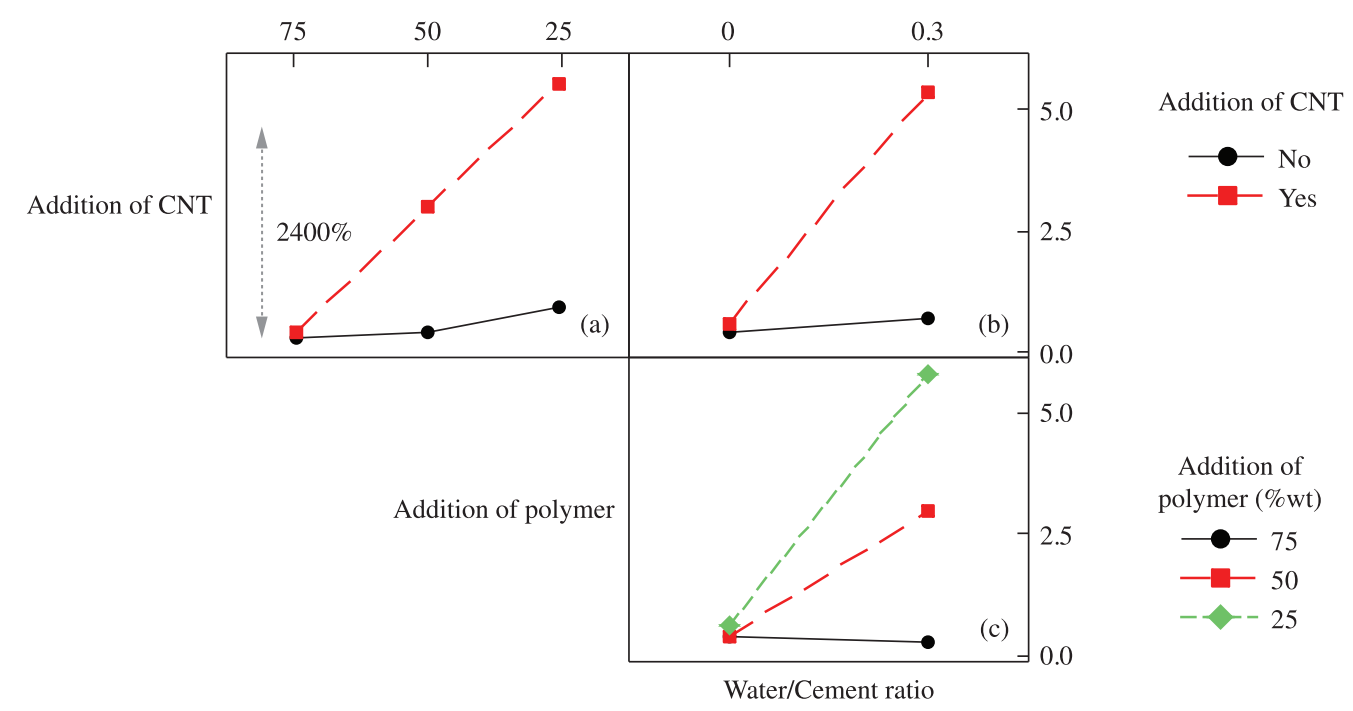

Figure 4. Interaction effect plot describing the addition of CNTs, the polymeric phase and water/cement ratio on the apparent porosity.

This result confirms that the effect of the cement phase and the CNT presence on the pore formation. The CNT provides a significant increase of porosity, which was also verified for the reference conditions. The addition of CNT affects the rheology of the system influencing the homogenization of the mixture, and therefore providing an increase of the apparent porosity of the material. The effect of water/cement ratio on the apparent porosity is more evident for the composites made with carbon nanotubes (see Figure $4 b$ ). Figure $4 \mathrm{c}$ indicates that the addition of water leads not only to the reduction of the density, but also to an increase of the porosity of the mixtures made with a higher percentage of cement phase. The level of $75 \%$ of polymeric phase (i.e. $25 \%$ of cement) was not affected by the water content, demonstrating that this effect is only significant when a large amount of cement is mixed.

\subsection{Compressive strength}

The values of the compressive strength of the composites range from $43.52 \mathrm{MPa}$ to $71.06 \mathrm{MPa}$. From observing Table 5, one can notice that the interactions between "addition of CNT and polymer" and "addition of polymer and water/cement ratio" were significant, showing P-values of 0.000 and 0.007 respectively. Figure 5 shows the interaction plot of "Addition of CNT and polymeric phase". The compressive strength decreased nearly $32 \%$ when CNTs were added, in particular for polymeric additions equal to $50 \%$ and $75 \%$. It is worth noticing that the addition of polymer into cement pastes hinders the rheology of the system, and consequently affects the dispersion of the carbon nanotubes. Higher compressive strength was achieved when small amount of polymer (25\%) was added (see Figure 5).

As discussed in paragraphs 3.1 and 3.2, the addition of carbon nanotubes provides the increase of porosity and, consequently, a strength reduction. The same behaviour can be observed for the reference conditions, where the presence of CNTs reduced the compressive strength for all the composite configurations (see Table 5).

The interaction plot between "water/cement ratio and addition of polymer" is shown in Figure 6. For all conditions,

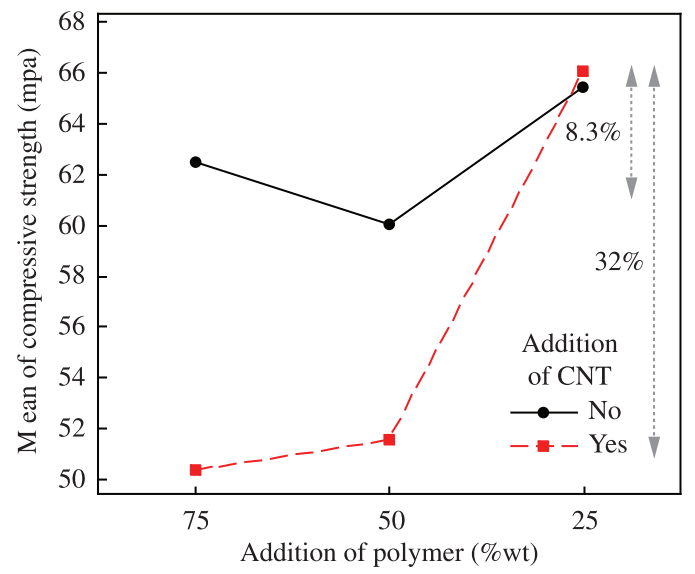

Figure 5. Interaction effect plot describing the addition of CNT and polymeric phase for compressive strength.

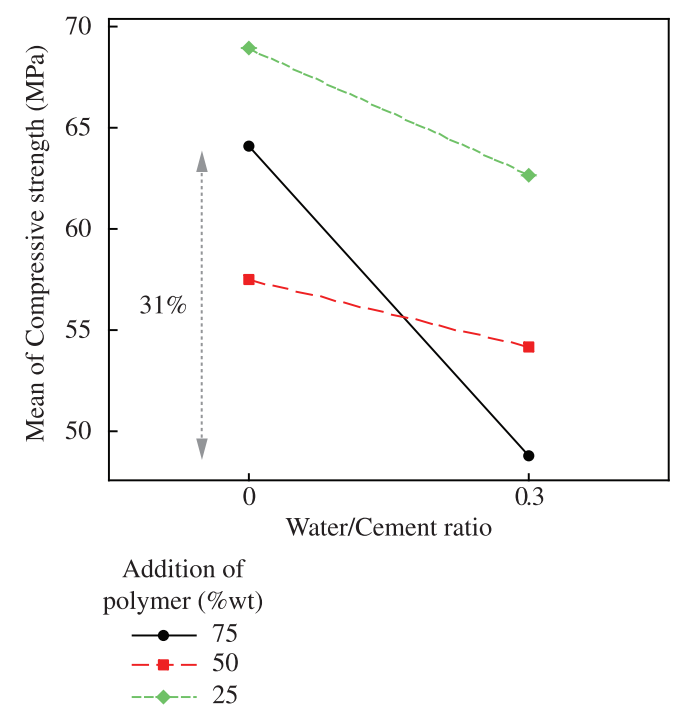

Figure 6. Interaction effect plot describing the water/cement ratio and addition of polymeric phase for compressive strength. 


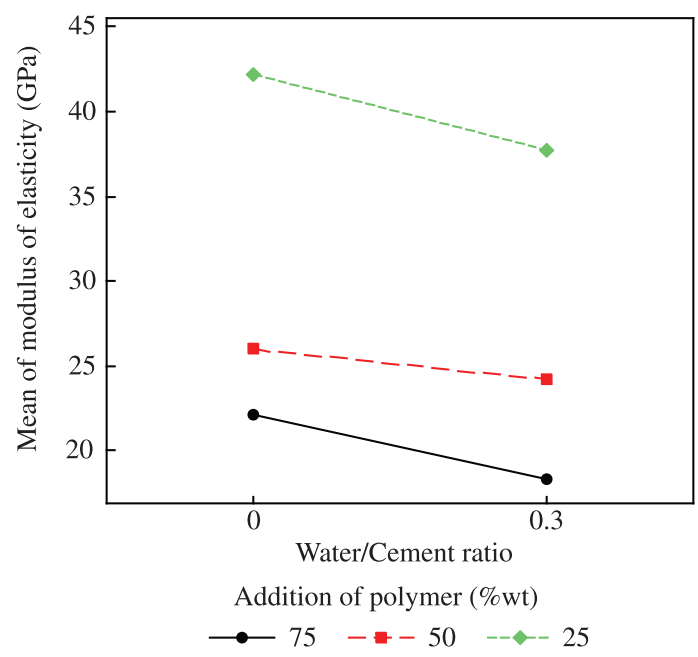

Figure 7. Interaction effect plot describing the water/cement ratio and addition of polymeric phase for the modulus of elasticity.

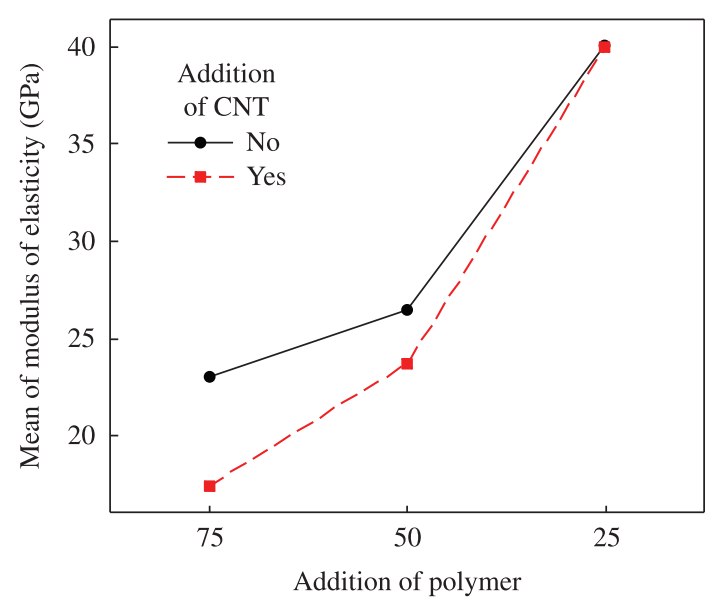

Figure 8. Interaction effect plot describing the addition of CNT and polymeric phase for modulus of elasticity.

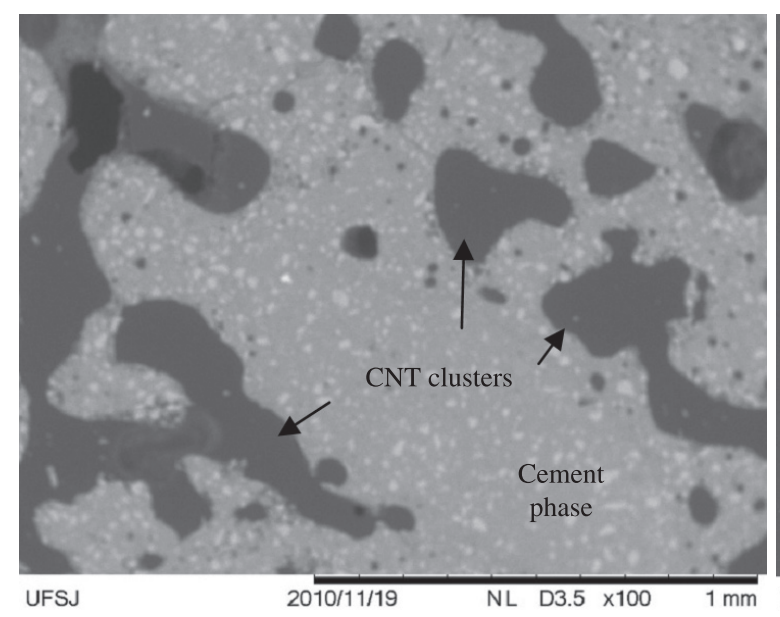

(a) the addition of water provided a significant reduction of the compressive strength. The composites made of $25 \%$ of resin (75\% of cement) exhibited superior strength, which can be attributed to the mechanical performance of the ceramics phase. Based on water/cement levels, a $31 \%$ variation was identified for composites made with $25 \%$ of polymer, revealing once again the effect of water into the cement phase, with the modification of hydration products and the following formation of pores.

\subsection{Modulus of elasticity}

The modulus of elasticity data varied between $16.1 \mathrm{GPa}$ and $42.3 \mathrm{GPa}$. The interactions of the factors "addition of CNT and polymeric phase" and "addition of polymer and water/cement ratio" were significant, exhibiting P-values of $0.000,0.006$ respectively. Figure 7 indicates that the presence of water provides a reduction in the Young's modulus of the composites for all the polymeric phase additions considered. The modulus of elasticity is higher when a lower percentage of polymer is added. The same behaviour was observed for the reference conditions (Table 5), showing that higher Young's modulus values are reached by those composites manufactured with large amount of cement phase.

Figure 8 shows the interaction effect plot between "addition of polymer and CNT" for the Young's modulus. Both the addition of carbon nanotubes and the presence of water provided a reduction to the modulus of elasticity. The analogous Young's modulus values for the reference samples exhibited a similar behaviour, showing a general reduction of the Young's modulus when carbon nanotubes were added. A possible explanation for this behaviour may be motivated by the non-uniform dispersion of the nanotubes.

The increase of the water content has been observed as being detrimental for the density and Young's modulus also in other polymer-cement composites ${ }^{9}$. Increase of polymer additions did also show a general decrease of porosity, density and modulus of elasticity of the composites ${ }^{9}$.

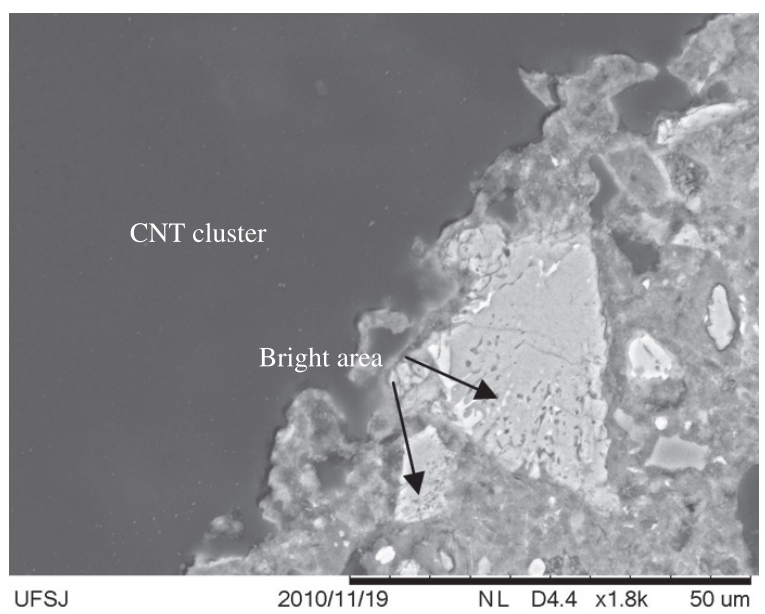

(b)

Figure 9. C6 composite images obtained by SEM in backscattered electron mode at (a) 100x of magnification (b) 1800x of magnification (ITZ). 
Figure 9 shows the image of the composite C6 obtained by SEM (Hitachi, model T-3000) using a magnification of $100 \times$ (a) and $1800 \times$ (b) in backscattered electron mode detector with an accelerating voltage of $15 \mathrm{kV}$. It is possible to observe a clustering of carbon nanotubes spread around the sample (dark spots, see Figure 9a), which is in accordance with the observations carried out by Makar and Beaudoin ${ }^{19}$. The carbon nanotubes tend to cluster due to Van der Waals forces, leading to changes in the distribution of the matrix. There is great interest in obtaining a correct dispersion of carbon nanotubes in polymer-cement matrix in order to obtain superior properties. Figure $9 \mathrm{~b}$ shows the interfacial transition zone (ITZ) between the carbon nanotube cluster and cement phase, exhibiting a good interface condition with no micro pores. Chemical components of high electron density have high backscatter coefficients, and appear bright in the backscattered images. The components of lower electron density, such as most cement hydration products such as $\mathrm{C}-\mathrm{S}-\mathrm{H}$ gel, accompanied by smaller amounts of ettringite and monosulfate, have lower backscatter coefficients and appear less bright ${ }^{20}$. The bright area found in Figure $9 \mathrm{~b}$ indicates the formation of unhydrated cement grains, which implies that the water content was not enough to fully hydrate the cement paste.

\section{Conclusions}

The work described in this paper is concerned with the impact of carbon nanotubes inclusions on the mechanical and physical properties of cement-polymer composites The polymer phase considered in these composites is a thermoset one (epoxy resin), while the matrix consisted in a ceramic phase (Portland cement). The main conclusions from the full-factorial design analysis carried out on 160 samples are the following:

- The addition of carbon nanotubes reduced the bulk density, the mechanical strength and the modulus of elasticity of the cement-based composites, and also contributed to increase the apparent porosity. The physical characteristics of the CNTs such as extremely low particle size and packing factor affect the material structure of the composite, increasing the amount of pores, and leading therefore to lower mechanical strengths.

- The addition of water provided the reduction of the bulk density, mechanical strength and modulus of elasticity, and also the increase of the apparent porosity. The water not only contributed to hydrate the cement, but also led the formation of pores in the cement phase, compromising therefore the mechanical properties. The water effect on the apparent porosity was more evident when CNT was added.

- The addition of polymeric phase provided lower bulk density and porosity, filling the pores formed by the cementitious phase.

- The microstructural analysis revealed a good interface condition between the CNT cluster and cement phase besides the presence of unhydrated cement grains.

- The composite manufactured with $25 \%$ of polymeric phase ( $75 \%$ of cementitious phase), without water and carbon nanotubes exhibited superior strength. However, the addition of carbon nanotubes into cementitious materials is of interest due to its potential piezoresistive capacity, acting as potential stress sensors for civil structures monitoring.

\section{References}

1. Melo VS, Calixto JMF, Ladeira LO and Silva AR. Macro-and micro-characterization of mortars produced with carbon nanotubes. ACI Materials Journal. 2011; 108:327-332.

2. Pizzutto CE, Suave J, Bertholdi J, Pezzin SH and Coelho LAF. Mechanical and dilatometric properties of carboxylated swcnt/epoxy composites: effects of the dispersion in the resin and in the hardener. Journal of Reinforced Plastics and Composites. 2010; 29:524-530. http://dx.doi. org/10.1177/0731684408099924

3. Cheng QF, Wang JP, Wen JJ, Liu CH, Jiang KL, Li QQ et al. Carbon nanotube/epoxy composites fabricated by resin transfer molding. Carbon. 2010; 48:260-266. http://dx.doi. org/10.1016/j.carbon.2009.09.014

4. Ohama Y. Recent progress in concrete-polymer composites. Advanced Cement Based Materials. 1997; 5:31-40. http:// dx.doi.org/10.1016/S1065-7355(96)00005-3

5. Van Gemert D, Czarnecki L, Maultzsch M, Schorn H, Beeldens A, Łukowski $\mathrm{P}$ et al. Cement concrete and concrete-polymer composites: two merging worlds. Cement and Concrete Research. 2005; 27:926-933. http://dx.doi.org/10.1016/j. cemconcomp.2005.05.004
6. Silva DA and Monteiro PJM. The influence of polymers on the hydration of portland cement phases analyzed by soft x-ray transmission microscopy. Cement and Concrete Research. 2006; 36:1501-1507. http://dx.doi.org/10.1016/j. cemconres.2006.05.010

7. Rai US and Singh RK. Synthesis and mechanical characterization of polymer-matrix composites containing calcium carbonate/ white cement filler. Materials Letters. 2003; 58:235-240. http:// dx.doi.org/10.1016/S0167-577X(03)00452-X

8. Sakai E and Sugita J. Composite mechanism of polymer modified cement. Cement and Concrete Research. 1995; 25:127-135. http://dx.doi.org/10.1016/0008-8846(94)00120-N

9. Panzera TH, Sabariz ALR, Strecker K and Borges PHR. Investigação do efeito da adição de resina epóxi no comportamento mecânico do cimento portland. In: Anais do $18^{\circ}$ Congresso Brasileiro de Engenharia e Ciência dos Materiais - CBCiMat; 2008; Porto de Galinhas. ABM; 2008.

10. Panzera TH, Sabariz ALR, Strecker K, Borges PHR, Vasconcelos DCL and Vasconcelos WL. Propriedades mecânicas de materiais compósitos à base de cimento portland e resina epóxi. Cerâmica. 2010; 56:77-82. http://dx.doi. org/10.1590/S0366-69132010000100013 
11. Panzera TH, Cota FP, Silva LJ, Christoforo AL and Borges PHR. Estudo das propriedades mecânicas de um material cerâmico-polimérico através da metodologia de planejamento fatorial de experimentos. In. Anais do $19^{\circ}$ Congresso Brasileiro de Engenharia e Ciência dos Materiais - CBCiMat; 2010; Campos do Jordão; 2010.

12. Yu X and Kwon E. A carbon nanotube/cement composite with piezoresistive properties. Smart Materials and Structures. 2009; 18:1-5. http://dx.doi.org/10.1088/0964-17 26/18/5/055010

13. Associação Brasileira de Normas Técnicas - ABNT. NBR 11578: Cimento Portland Composto. Rio de Janeiro: 1991.

14. Werkema MCC and Aguiar S. Planejamento e análise de experimentos: como identificar e avaliar as principais variáveis influentes em um processo. Belo Horizonte: Fundação Christiano Ottoni, Escola de Engenharia da UFMG; 1996.

15. Montgomery DC. Introduction to statistical quality control. New York: John Wiley \& Sons; 1997.
16. Jeff $\mathrm{Wu} \mathrm{CF}, \mathrm{Wu} \mathrm{CF}$ and Hamada M. Experiments: planning, analysis, and parameter optimization. New York: John Wiley \& Sons; 2000.

17. British Standards - BS. BS EN ISO 604: Plastics - Determination of compressive properties. BS; 2003.

18. British Standards - BS. BS EN ISO 10545-3: Determination of water absorption, apparent porosity, apparent relative density and bulk density. BS; 1997.

19. Makar JM and Beaudoin JJ. Carbon nanotubes and their application in the construction industry. In: Proceedings of the International Symposium on Nanotechnology in Construction; 2003; Paisley. Paisley; 2003.

20. Diamond S. The microstructure of cement paste and concrete - a visual primer. Cement and Concrete Composites. 2004; 26:919-933. http://dx.doi.org/10.1016/j. cemconcomp.2004.02.028 